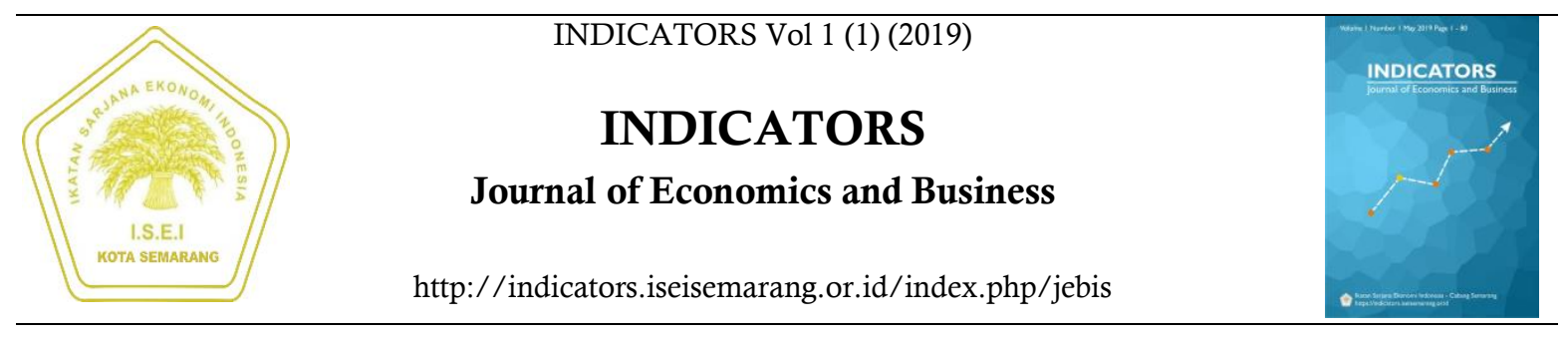

\title{
Analisis Efisiensi Produksi Industri Mikro Kecil Batik di Kota Pekalongan Tahun 2016
}

Eko Nur Aji ${ }^{\otimes}$

Jurusan ekonomi pembangunan, Fakultas Ekonomi, Universitas Negeri Semarang

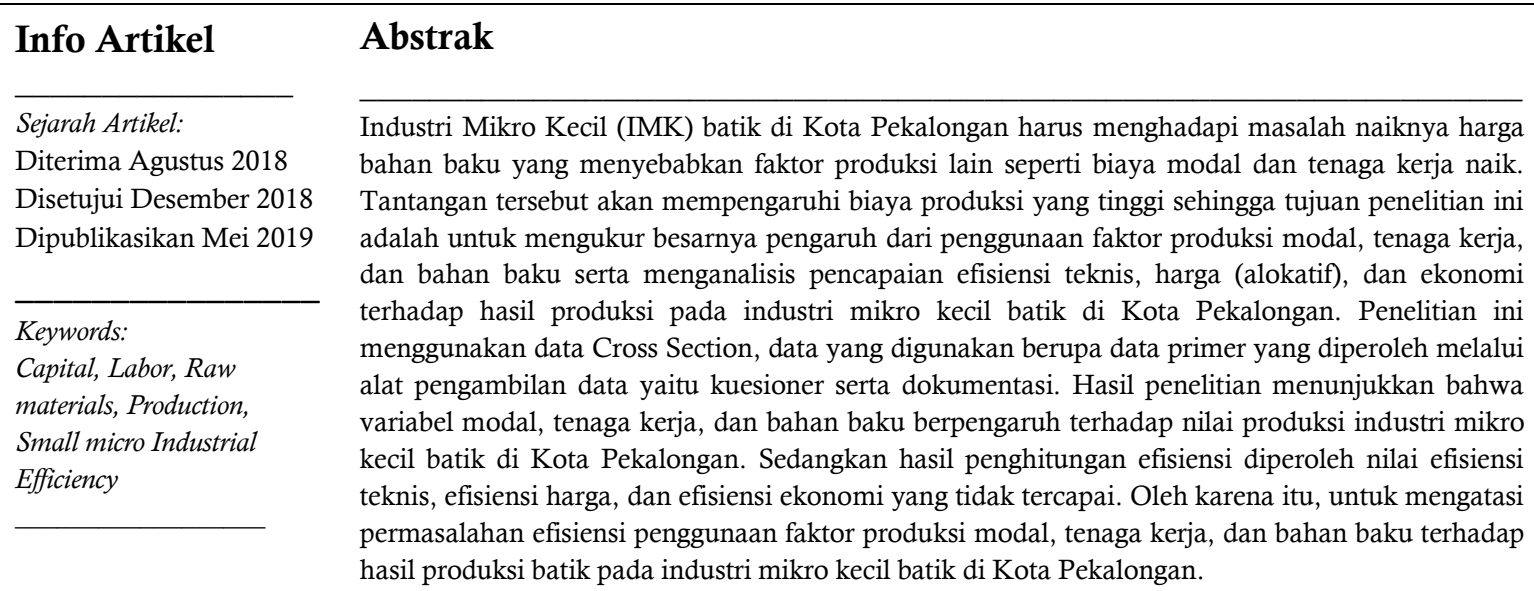

Abstract

Industry Small Micro (IMK) in Kota Pekalongan batik had to face the problem of rising prices of raw materials led to other factors of production such as capital and labor costs rise. These challenges will affect production costs are high so the goal of this study was to measure the effect of the use of factors of production, capital, labor, and raw materials as well as to analyze the achievement of technical efficiency, the price of (allocative), and the economics of the production on an industrial micro batik in Pekalongan. This study uses data Cross Section, the data used are primary data obtained through data retrieval tool is a questionnaire and documentation. The results showed that the variables of capital, labor, and raw materials affect the value of industrial production of small micro batik in Pekalongan. While the results of the calculation of the efficiency values obtained technical efficiency, price efficiency, and economic efficiency is not achieved. Therefore, to overcome the problem of efficient use of production factors of capital, labor, and raw materials to the production of small micro batik industry in Pekalongan batik.

\footnotetext{
$\triangle$ Alamat korespondensi:

J1. Erlangga Tengah No.17, Semarang, 50229

E-mail: ekonuraji@gmail.com
} 


\section{PENDAHULUAN}

Pembangunan ekonomi merupakan salah satu cara untuk mencapai keadaan yang lebih baik. Pembangunan ekonomi pada hakekatnya adalah serangkaian usaha kebijaksanaan yang bertujuan untuk meningkatkan taraf hidup masyarakat, memperluas kesempatan kerja dan mengarahkan pembagian pendapatan secara merata.
Oleh karena itu, di dalam proses pembangunan IMK (Industri Mikro Kecil) di Indonesia dijadikan sebagai prioritas pembangunan dan diharapkan mempunyai peranan penting sebagai sektor pemimpin (leading sector). Sektor pemimpin yang dimaksud adalah sebagai sektor pendorong untuk berkembangnya sektor lain seperti sektor jasa, pertanian, dan sektor lainnya.

Tabel 1. Kontribusi Ekonomi IMK di Indonesia Tahun 2013-2015

\begin{tabular}{lccccc}
\hline \multirow{2}{*}{ Indikator } & \multirow{2}{*}{ Satuan } & \multicolumn{3}{c}{ Tahun } & \multirow{2}{*}{ Rata-rata } \\
\cline { 3 - 5 } & & 2013 & 2014 & 2015 & \\
\hline Nilai Tambah & Juta Rupiah & 300.777 .949 & 202.198 .473 & 220.740 .544 & 241.238 .989 \\
Nilai Input & Juta Rupiah & 300.777 .949 & 311.111 .481 & 349.626 .357 & 320.505 .262 \\
Nilai Output & Juta Rupiah & 489.861 .304 & 513.309 .953 & 570.366 .901 & 524.512 .719 \\
\hline
\end{tabular}

Sumber: BPS Jawa Tengah dalam angka 2015

Pada tabel 1 menunjukkan kontribusi IMK di Indonesia tahun 2013-2015 seperti Nilai tambah dari IMK dari tahun 2013-2015 mencapai rata-rata 241.238 .989 juta, Nilai Input dari IMK mencapai rata-rata 320.505.262 juta, dan Nilai Output IMK mencapai rata-rata 524.512.719 juta. Hal ini membuktikan bahwa IMK di Indonesia mempunyai kontribusi dalam perekonomian. Sehingga IMK di Indonesia dapat menjadi prioritas pembangunan dan diharapkan peranan penting sebagaI sektor pemimpin dari sektor lainnya.

IMK batik di Jawa Tengah yang terkenal adalah IMK batik di Kota Pekalongan. Kota Pekalongan dikenal dengan julukan kota batik, karena IMK batik di Kota Pekalongan memiliki corak yang khas dan variatif. Kota Pekalongan masuk jaringan kota kreatif UNESCO (United Nations Educational, Scientific, and Cultural Organization)dalam kategori crafts \& folk art pada Desember 2014 dan memiliki city branding World's city of Batik. Hal ini membuktikan kalau IMK batik di Kota Pekalongan perlu dikembangkan lebih lanjut agar dapat bersaing dengan Kota/Kabupaten yang lain di Jawa Tengah. Salah satu contoh IMK di Indonesia adalah IMK batik di Kota Pekalongan. Pada tanggal 2 Oktober 2009, UNESCO mendeklarasikan Batik Indonesia sebagai warisan budaya dunia. Peristiwa tersebut mestinya dimaknai oleh segenap negeri ini untuk meningkatkan harkat hidup para pengrajin dan buruh batik tradisional. UNESCO juga mendeklarasikan Kota Pekalongan sebagai daerah yang dijuluki kota Kreatif dalam mengembangkan industri batik.

Pada tanggal 3 Oktober 2011 terdapat dua sentra batik yaitu sentra batik Kauman dan sentra batik Pesindon telah diresmikan sebagai sentra Industri Batik. Hal-hal tersebut menjadikan kota Pekalongan patut untuk dikembangkan agar lebih menjadi kota maju khususnya dalam mengembangkan industri batik. Julukan Kota sentra batik ternyata dalam kenyataannya Industri mikro kecil di Kota Pekalongan harus menghadapi tantangan yaitu naiknya harga bahan baku utama.

Tabel 2. Harga Bahan Baku Utama Industri Batik di Kota Pekalongan Tahun 2013-2015

\begin{tabular}{lccc}
\hline \multicolumn{1}{l}{ Bahan Baku } & 2013 & 2014 & 2015 \\
\hline $\begin{array}{l}\text { Kain Mori } \\
\text { (meter) }\end{array}$ & Rp25.000 & Rp25.000 & Rp30.000 \\
$\begin{array}{l}\text { Malam/Lilin } \\
\text { (kg) }\end{array}$ & Rp80.000 & Rp80.000 & Rp85.000 \\
Wax/Pewarna & Rp20.000 & Rp20.000 & Rp21.000 \\
\hline \multicolumn{2}{l}{ Sumber: Berbagai Sumber (Data diolah) }
\end{tabular}


Tabel 3. Jumlah Tenaga Kerja Industri Batik di Kota Pekalongan Tahun 2013-2015

\begin{tabular}{lrrr}
\hline $\begin{array}{l}\text { Industri } \\
\text { Batik }\end{array}$ & 2013 & 2014 & 2015 \\
\hline $\begin{array}{l}\text { Jumlah } \\
\text { Unit }\end{array}$ & 860 & 861 & 1.077 \\
$\begin{array}{l}\text { Tenaga } \\
\text { Kerja }\end{array}$ & 11.811 & 12.004 & 12.690 \\
$\begin{array}{l}\text { Sumber: Disperindagkop } \\
\text { dalam angka 2015. }\end{array}$ & Kota & Pekalongan \\
\end{tabular}

Industri batik di Kota Pekalongan mengalami kenaikan harga bahan baku yang mengakibatkan biaya produksi meningkat. Tingginya biaya produksi batik pada akhirnya akan mempengaruhi modal dan tenaga kerja yang digunakan. Harga bahan baku yang tinggi maka akan berpengaruh terhadap faktor produksi lain yaitu modal, semakin banyak bahan baku yang digunakan semakin banyak pula modal yang dikeluarkan untuk menjalankan industri (Hanifah, 2013).

Industri batik di Kota Pekalongan yang mendapatkan tekanan dari naiknya harga bahan baku adalah Industri Mikro Kecil (IMK). Sehingga perlu dilakukan analisis untuk mengidentifikasi faktor input yang mempengaruhi produksi serta efisiensi teknis, efisiensi harga, dan efisiensi ekonomi penggunaan faktor input terhadap output industri batik di Kota Pekalongan.

\section{METODE PENELITIAN}

Penelitian ini menggunakan metode analisis regresi linier berganda dengan software $E$ Views 9 untuk mengukur faktor-faktor yang mempengaruhi produksi industri mikro kecil batik di Kota Pekalongan dan metode analisis efisiensi produksi frontier dengan pendekatan fungsi produksi Cobb-Douglas menggunakan software frontier $4.1 c$ untuk menganalisis pencapaian efisiensi secara teknis, harga, maupun ekonomi. Model yang digunakan adalah model fungsi produksi Cobb-Douglas yang digunakan adalah sebagai berikut:

$\operatorname{LnY}=\beta_{0}+\beta_{1} \operatorname{LnX}_{1}+\beta_{2} \operatorname{LnX}_{2}+\beta_{3} \operatorname{LnX}_{3}+u_{i} .$. (1)

Keterangan:

$$
\begin{array}{ll}
\mathrm{Y} & : \text { Produksi (\%) } \\
\mathrm{X}_{1}, \mathrm{X}_{2}, \mathrm{X}_{3}: \text { Input yang digunakan } \\
\mathrm{X}_{1} & : \text { Modal (\%) } \\
\mathrm{X}_{2} & : \text { Tenaga Kerja (\%) } \\
\mathrm{X}_{3} & : \text { Bahan Baku (\%) } \\
\beta & : \text { Koefisien Regresi } \\
\mathrm{Ln} & : \text { Logaritma Natural } \\
\mathrm{u}_{\mathrm{i}} & : \text { Error Term }
\end{array}
$$

Penggunaan model ini tepat untuk melihat perilaku data dari masing-masing faktor produksi sehingga data lebih dapat menginterpretasi data.

\section{HASIL DAN PEMBAHASAN}

Penyusunan penelitian ini menggunakan objek penelitian dari pengusaha industri batik di Kota Pekalongan. Jumlah pengusaha batik yang dijadikan sampel adalah sebanyak 50 pengusaha batik. Jumlah sampel didapatkan dari pengalian 10x dari variabel yang dipakai dalam penelitian (Sugiyono, 2010). Sampel dalam penelitian ini yaitu industri batik mikro kecil (industri kecil). Penelitian ini mencakup data mengenai modal, jumlah tenaga kerja, bahan baku, dan produksi yang dihasilkan pada industri batik di Kota Pekalongan.

Tabel 5. Hasil Olah Data Regresi Linier Berganda

\begin{tabular}{lllll}
\hline Independen & Koefisien & Std. Error & F-Statistik & AdjustedR $^{2}$ \\
\hline C (Contant) & 3,059 & 0,514 & 597,805 & 0,973 \\
Modal & 0,604 & 0,068 & & \\
TK & 0,092 & 0,033 & & \\
BB & 0,227 & 0,048 & & \\
\hline
\end{tabular}

Sumber: Data Primer diolah dengan E-views 9, 2016. 
Dari hasil estimasi Tabel 5 dapat dituliskan persamaan sebagai berikut:

$\mathrm{LnPROD}_{\mathrm{t}}=3,059+0,604 \mathrm{LnMODAL}_{\mathrm{t}}+0,092$ $\mathrm{LnTK}_{\mathrm{t}}+0,227 \mathrm{LnBB}_{\mathrm{t}}+\mathrm{u}_{\mathrm{t}}$

Persamaan regresi di atas dapat dijelaskan sebagai berikut:

Nilai C (Constant) sebesar 3,059 artinya apabila peningkatan variabel modal, tenaga kerja, dan bahan baku tetap atau nilainya adalah 0 maka produksi yang dihasilkan sebesar anti log $3,059=1.069,054$. Koefisien LnMODAL $_{\mathrm{t}}$ sebesar 0,604 artinya apabila terjadi peningkatan modal sebesar $1 \%$ maka produksi akan mengalami peningkatan sebesar $0,60 \%$ dengan asumsi variabel yang lain tetap. Koefisien $\mathrm{LnTK}_{\mathrm{t}}$ sebesar 0,092 artinya apabila terjadi peningkatan tenaga kerja sebesar 1\% maka produksi akan mengalami peningkatan sebesar 0,09\% dengan asumsi variabel yang lain tetap. Koefisien $\mathrm{LnBB}_{\mathrm{t}}$ sebesar 0,227 artinya apabila terjadi peningkatan tenaga kerja sebesar 1\% maka produksi akan mengalami peningkatan sebesar $0,22 \%$ dengan asumsi variabel yang lain tetap.

Persamaan di atas menunjukkan hubungan antara faktor produksi modal, tenaga kerja, dan bahan baku dengan hasil produksi batik. Ketiga variabel independen tersebut menunjukkan hubungan positif, yang berarti bahwa ketiga variabel independen memiliki pengaruh yang positif terhadap hasil produksi industri mikro kecil batik di Kota Pekalongan.

Tabel 6. Hasil Estimasi Fungsi Produksi Frontier Stokastik

\begin{tabular}{llll}
\hline No. & Variabel & Koefisien & t-ratio \\
\hline 1 & Konstanta & 3.0795 & 7.2684 \\
2 & LX $_{1}$ (Modal) & 0.6003 & 9.8365 \\
3 & LX $_{2}$ (Tenaga Kerja) & 0.0933 & 3.1449 \\
4 & LX $_{3}$ (Bahan Baku) & 0.2298 & 5.2090 \\
5 & Mean Efisiensi teknis & 0.9993 & \\
6 & Mean Inefisiensi teknis & 0,0007 & \\
7 & Return to Scale & 0,9234 & \\
8 & $\mathrm{~N}$ & 50 & \\
\multicolumn{2}{ll}{ Sumber: Data Primer diolah dengan software frontier 4.1, 2016. }
\end{tabular}

Model yang didapat sebagai berikut:

$\mathrm{LnPROD}_{\mathrm{t}}=3.079+0.6003 \mathrm{LnMODAL}_{\mathrm{t}}+$ $0.0933 \mathrm{LnTK}_{\mathrm{t}}+0.2298 \mathrm{LnBB}_{\mathrm{t}}+\mathrm{u}_{\mathrm{t}}$

Berdasarkan hasil estimasi fungsi produksi industri mikro kecil batik di Kota Pekalongan dengan pendekatan produksi frontier stokastik, input awal yang digunakan telah ditransformasikan ke dalam bentuk log natural (Ln), maka satuan yang dituliskan menjadi persen, sedangkan untuk melihat signifikansi dari pengaruh variabel terhadap variabel terikat secara parsial digunakan uji t-statistik. Signifikansi pengaruh tersebut dapat diestimasi dengan membandingkan antara t-ratio dengan tTabel pada $\alpha$ dan degree of freedom (df) tertentu (Sucihatiningsih, 2013). Pada penelitian ini di dapat nilai t-Tabel $=1.67866$ di peroleh dari $(\alpha=$ 0,05 dan df = 46). Koefisien elastisitas masingmasing input dalam industri mikro kecil batik adalah sebagai berikut:

Nilai konstanta memiliki koefisien elastisitas sebesar 3,079. Hal ini berarti apabila peningkatan variabel modal, tenaga kerja, dan bahan baku adalah 0 maka nilai variabel produksi sebesar anti $\log 3,079=1.200,881$. Variabel modal memiliki koefisien elastisitas sebesar 0,6003 . Hal ini berarti bila penggunaan input modal dinaikkan sebesar 1\% maka akan diperoleh peningkatan output produksi sebesar $0,60 \%$. Sedangkan untuk variabel modal signifikan terhadap hasil produksi hal ini ditunjukkan oleh nilai t-ratio $>$ t-Tabel $(\alpha=0,05$ dan df =46) sebesar 9,8365 $>1,69913$ sehingga 
jika penggunaan input modal ditambah maka akan meningkatkan output produksi. Variabel tenaga kerja memiliki koefisien elastisitas sebesar 0,0933. Hal ini berarti bila penggunaan input tenaga kerja dinaikkan sebesar 1\% maka akan diperoleh peningkatan output produksi sebesar 0,09\%. Sedangkan untuk variabel tenaga kerja signifikan terhadap hasil produksi hal ini ditunjukkan oleh nilai t-ratio $>$ t-Tabel $(\alpha=0,05$ dan $\mathrm{df}=46$ ) sebesar 3,1449 > 1,69913 sehingga jika penggunaan input tenaga kerja ditambah maka akan meningkatkan output produksi.

Variabel bahan baku memiliki koefisien elastisitas sebesar 0,2298. Hal ini berarti bila penggunaan input bahan baku dinaikkan sebesar 1\% maka akan diperoleh peningkatan output produksi sebesar 0,22\%. Sedangkan untuk variabel bahan baku signifikan terhadap hasil produksi hal ini ditunjukkan oleh nilai t-ratio $>$ tTabel ( $\alpha=0,05$ dan df =46) sebesar 3,1449> 1,69913 sehingga jika penggunaan input bahan baku ditambah maka akan meningkatkan output produksi.

Berdasarkan olah data dari software frontier 4.1c dengan fungsi production function diperoleh Nilai rata-rata efisiensi teknis industri mikro kecil batik menunjukkan tingkat efisiensi yang dicapai adalah mendekati nilai maksimum atau angka 1 yaitu sebesar 0,9993.

Indikator efisiensi dapat dikatakan tercapai secara teknis apabila nilai yang dihasilkan adalah sama dengan angka 1, sedangkan apabila nilai lebih kecil atau lebih besar dari angka 1 maka dapat disimpulakan secara teknis belum tercapai efisiensi. Dari hasil yang diperoleh adalah kurang dari angka 1 maka dapat disimpulkan bahwa industri mikro kecil batik di Kota Pekalongan belum mencapai efisiensi secara teknis.

Hasil perhitungan efisiensi teknis ini menunjukkan bahwa rata-rata industri batik sampel dapat mencapai 99 persen dari potensial produksi yang diperoleh dengan menggunakan kombinasi faktor produksi yang dikorbankan dan masih terdapat peluang sebesar 1 persen untuk meningkatkan produksi batik di daerah penelitian.

Secara teknis industri mikro kecil batik belum mampu mengkombinasikan input yang benar-benar digunakan untuk menghasilkan output yang maksimal secara efisien. Hal ini sesuai dengan hasil penelitian oleh Pradana, 2013 bahwa penggunaan faktor-faktor produksi dalam industri mikro kecil keripik tempe tidak efisien secara teknis sehingga perlu dilakukan pengurangan input.

Secara umum, industri batik berskala kecil memiliki anggapan bahwa apabila penggunaan faktor-faktor produksi ditambah penggunaanya maka akan menghasilkan produksi yang banyak pula. Padahal tidak demikian, sebenarnya penggunaan faktor-faktor produksi harus digunakan secara proposional agar tercipta efisiensi teknis.

Berdasarkan nilai skala proporsional lebih kecil dari 1 menunjukkan bahwa proporsi penambahan faktor produksi pada industri mikro kecil batik akan menghasilkan tambahan produksi dengan proporsi yang kecil. Sehingga penggunaan faktor-faktor produksi yang berlebihan justru akan membuat produktivitas dan hasil produksi menjadi turun.

Keadaan seperti ini sangat sejalan dengan teori pertumbuhan ekonomi hasil yang semakin berkurang The Law of Diminishing Return dari David Ricardo. Menyatakan bahwa hasil produksi industri mikro kecil batik akan menurun kerena terlalu banyak dalam penggunaan faktor produksi.

Nilai produk marginal (NPM) di sini diperoleh dari nilai koefisien masing-masing variabel dikalikan dengan rata-rata pendapatan total dibagi dengan rata-rata biaya masingmasing variabel tersebut. Berikut adalah hasil frontier dengan fungsi cost function: 
Tabel 7. Jumlah Total dan Rata-rata Biaya Industri Mikro Kecil Batik di Kota Pekalongan

\begin{tabular}{lrrr}
\hline Keterangan & Jumlah Total $(\mathrm{Rp})$ & Rata-rata $(\mathrm{Rp})$ & \multicolumn{2}{c}{ Koefisien } \\
\hline Modal $\left(\mathrm{X}_{1}\right)$ & 2.484 .000 .000 & 49.680 .000 & 0.6684 \\
Tenaga Kerja $\left(\mathrm{X}_{2}\right)$ & 608.550 .000 & 12.171 .000 & 0.0675 \\
Bahan Baku $\left(\mathrm{X}_{3}\right)$ & 1.504 .980 .000 & 30.099 .600 & 0.1924 \\
Produksi $(\mathrm{Y})$ & 3.029 .000 .000 & 60.580 .000 & \\
\hline
\end{tabular}

Sumber: Data Primer diolah dengan software frontier 4.1c, 2016.

Berdasarkan hasil perhitungan $\mathrm{NPM}_{\mathrm{xi}}$ untuk masing-masing faktor produksi di atas diketahui besarnya efisiensi harga (alokatif) adalah sebesar 0,5125. Hal ini berarti industri mikro kecil batik di Kota Pekalongan tidak mencapai efisien secara harga, sebab nilai efisiensi harganya lebih kecil dari 1.

Sehingga diketahui industri batik di Kota Pekalongan tidak mampu memaksimalkan keuntungan yang potensial dapat diperoleh dari industri batik. Hasil perhitungan untuk masingmasing faktor produksi menunjukkan bahwa faktor produksi modal meningkat akibat harga bahan baku naik, jumlah biaya tenaga kerja meningkat dan bahan baku juga meningkat. Oleh karena itu, perlu dilakukan pengurangan input dalam penggunaan faktor-faktor produksi agar dapat mencapai efisien. Hal ini sesuai dengan hasil penelitian Pradana 2013, pada industri mikro kecil keripik tempe tidak mampu memaksimalkan keuntungan yang potensial.

Efisiensi ekonomi dapat dicapai apabila efisiensi teknis dan efisiensi harga telah dicapai, maka dapat dihitung besarnya efisiensi ekonomi sebagai berikut:

$$
\begin{aligned}
\text { EE: ET.EH } & =0,9993 \times 0,5125 \\
& =0,5121
\end{aligned}
$$

Jadi besarnya efisiensi ekonomi pada industri mikro kecil batik di Kota Pekalongan adalah sebesar 0,5121. Hal ini menunjukkan industri mikro kecil batik di Kota Pekalongan tidak efisien secara ekonomis sehingga perlu dilakukan pengurangan input agar tercapai efisiensi khususnya pada faktor produksi modal yang digunakan. Penggunaan modal pada industri meningkat akibat harga bahan baku naik. Pencapaian efisiensi ekonomis dapat dicapai dengan mengoptimalkan modal yang digunakan, penggunaan tenaga kerja yang produktif dan bahan baku berkualitas guna hasil yang diperoleh dapat meningkat. Hal ini sesuai dengan hasil penelitian oleh Pradana 2013, bahwa hasil menunjukkan penggunaan faktor produksi tidak efisien secara ekonomi pada industri mikro kecil keripik tempe.

Return to scale merupakan suatu keadaan di mana output meningkat sebagai respon adanya kenaikkan yang proposional dari seluruh input (Nicholson, 2002). Seperti yang diketahui bahwa pada fungsi Cobb-Douglas, koefisien tiap variabel independen merupakan elastisitas terhadap variabel dependen. Dapat diketahui return to scale dari industri mikro kecil batik di Kota Pekalongan melalui penjumlahan setiap variabel independen. Nilai koefisien berdasarkan hasil perhitungan software frontier dengan mode production function adalah sebagai berikut:

$$
\begin{aligned}
\text { Return to scale }= & \beta_{1} X_{1}+\beta_{2} X_{2}+\beta_{3} X_{3} \\
= & 0,6003+0,0933+ \\
& 0,2298 \\
= & 0,9234
\end{aligned}
$$

Nilai Decreasing return to scale sebesar 0,9234 itu sendiri dapat diartikan apabila terjadi penambahan faktor produksi sebesar 1 persen maka akan menurunkan output produksi sebesar 0,9234 persen dengan proporsi skala yang kecil. Berdasarkan hasil efisisensi, penggunaan faktor produksi modal pada industri mikro kecil batik di Kota Pekalongan meningkat karena harga bahan baku naik.

Nilai efisiensi dan return to scale menunjukkan bahwa industri batik di Kota Pekalongan perlu mengoptimalkan penggunaan modal yang digunakan, penggunaan tenaga kerja ahli yang lebih produktif, dan penggunaan bahan baku yang berkualitas agar dapat memaksimalkan produksi yang dihasilkan. Keadaan ini di perkuat oleh Pratiwi, 2014 bahwa 
hasil efisiensi untuk penggunaan modal berlebihan pada industri besar dan sedang di Provinsi Bali.

\section{SIMPULAN}

Berdasarkan hasil penelitian dan pembahasan menggunakan analisis regresi dan analisis efisiensi frontier stokastik diperoleh simpulan bahwa terdapat pengaruh yang signifikan secara parsial dan secara bersamasama antara faktor-faktor input modal, tenaga kerja dan bahan baku terhadap output produksi pada industri mikro kecil batik di Kota Pekalongan.

Efisiensi teknis, harga (alokatif), dan ekonomi penggunaan faktor produksi pada industri mikro kecil batik di Kota Pekalongan tidak mencapai efisien. Hal ini disebabkan adanya hubungan dengan kondisi decreasing return to scale yang dapat menunjukkan hasil produksi lebih kecil dibandingkan penggunaan faktor produksi modal, tenaga kerja, dan bahan baku dalam proses produksi. Sehingga perlu dilakukan pengurangan penggunaan faktorfaktor produksi pada faktor produksi modal agar dapat mengoptimalkan penggunaan tenaga kerja dan penggunaan bahan baku yang lebih berkualitas.

\section{DAFTAR PUSTAKA}

Badan Pusat Statistik Jawa Tengah, 2016. Usaha Mikro dan Kecil. www.bps.gp.id. Di akses: 307-2016 (14:04 WIB).

Berita Satu, 2016. Harga Bahan Baku Batik di Pekalongan Melonjak. http://beritasatu.com/ . Di akses: 31-7-2016 (12:56 WIB).

Blok Kota Kreatif Dunia, 2013. World City of Batik: Prestasi Kota Pekalongan. http://kotakreatifdunia.blokspot.co.id/ . Di akses: 31-7-2016 (12:40 WIB).

Gujarati, Damodar N. 2010. Dasar-dasar Ekonometrika Buku 1. Jakarta: Salemba Empat.
Hanifah, Ristia Nur, 2013. Efisiensi Penggunaan FaktorFaktor Produksi Pada Industri Menengah, Kecil Dan Rumah Tangga Mebel Di Kabupaten Blora. Economics Development Analysis Journal 2 (2) (2013).

Hidayat, Yusmar Ardhi, 2012. Efisiensi Produksi Kain Batik Cap. Jurnal Ekonomi Pembangunan. Vol. 13, No. 1, Juni 2012, hlm.79-95.

Joesron, Tati Suhartati dan Fathurrozi. 2003. Teori Ekonomi Mikro. Jakarta: Salemba Empat.

Nicholson, Walter. 2002. Mikroekonomi Intermediate dan Aplikasinya. Jakarta: Erlangga.

Nugroho, Budi Arif, 2015. Analisis Fungsi Produksi Dan Efisiensi Jagung Di Kecamatan Patean Kabupaten Kendal. Junal Jejak Vol 8 (2) (2015): 163-177.

Pradana, Adyarta, 2013. Analisis Faktor-faktor yang Mempengaruhi Efisiensi Industri Rumah Tangga Keripik Tempe di Kabupaten Blora. Economics Development Analysis Journal 2 (2) (2013).

Prajanti, Sucihatingsih Dian Wisika. 2013. Metode Analysis Efisiensi Produksi dan Pengambilaan Keputusan Bidang Ekonomi Pertanian. Semarang: Unnes Presss.

Sapa Kabar Blogspot. Penghargaan Kota Kreatif dari UNESCO. http://sapakabar.blogspot.co.id/ . Di akses: 31-7-2016 (12:40 WIB).

Soekartawi. 2001. Agribisnis, Teori dan Aplikasinya. Jakarta: Raja Grafindo Persada.

Suara Merdeka, 2016. Pemkot Diminta Jamin Ketersediaan Bahan Baku Batik. http://berita.suaramerdeka.com/ . Di akses: 31-7-2016 (12:56 WIB).

Sugiyono, Prof. DR. 2010. Statistika Untuk Penelitian. Bandung: Indonesia (IKAPI).

UU No. 13 Tahun 2003 Tentang Ketanagakerjaan.

UU No. 20 Tahun 2008 Pasal 1 dan Pasal 6 Tentang Usaha Mikro Kecil dan Menengah (UMKM).

UU No. 32 Tahun 2004 Pasal 1 Tentang Pemerintahan Daerah.

Wijandi, Soesarsono. 2004. Pengantar Kewiraswastaan. Bandung: Sinar Baru Algensindo.

Wuryanto, Teguh Adi. 2011. Analisis Industri Batik Tulis Di Kelurahan Kalinyamat Wetan Dan Kelurahan Bandung Kota Tegal. Skripsi. UNDIP. 